\title{
Outcomes of Traumatic Pancreatic Injuries in Pediatric and Adult Patients: A Retrospective Study Involving Four Trauma Centers
}

\author{
Toni lurcotta ${ }^{1,2, *}$ Poppy Addison ${ }^{1,2, *}$ Leo I. Amodu ${ }^{1,2}$ Meredith Akerman ${ }^{3}$ Horacio L. Rilo ${ }^{1,2}$
}

${ }^{1}$ Department of Surgery, Hofstra Northwell School of Medicine,

Address for correspondence Horacio L. Rilo, MD, Department of Hempstead, New York, United States Surgery, Hofstra Northwell School of Medicine, 400 Community Drive,

2 Department of Surgery, Pancreas Disease Center, Northwell Health, Manhasset, NY 11040, United States (e-mail: Hrilo@northwell.edu).

Great Neck, New York, United States

${ }^{3}$ Department of Biostatistics, Feinstein Institute for Medical

Research, Manhasset, New York, United States

J Child Sci 2017;7:e136-e141.

\begin{abstract}
Keywords

- adult

- pancreas

- pediatric

Traumatic injuries of the pancreas are rare and affect both children and adults. Very little has been done to investigate differences in outcome between these two age groups. We performed a retrospective review of cases in four trauma hospitals to determine the differences in outcomes between pediatric and adult patients with traumatic pancreatic injuries. A retrospective chart review was performed for 69 pediatric and adult patients seen at four trauma centers in our health system between 1990 and 2014. The Mann-Whitney's U-test was used to compare continuous variables, while the chi-square and Fisher's exact tests were used for categorical variables. Mortality was determined using the Social Security Death Master File. In this study, 26 pediatric and 43 adult patients were included. Median ages were 11.4 and 42.3 years, respectively. There were significant differences in mechanism of blunt injury between pediatric and adults (motor vehicle collisions $=17.4 \mathrm{vs.} 64.9 \%$, bicycle accidents $=43.5$ vs. $0.0 \%$; $p$-value for both comparisons $<0.0001$ ), median injury severity score (6.5 vs. $12 ; p=0.030$ ), surgical management (30.8 vs. $67.4 \%$; $p=0.003$ ), and postinjury pancreatitis (57.7 vs. $20.9 \% ; p=0.002)$. Median hospital length of stay was 5 versus 11 days $(p=0.005)$, respectively. There were no differences in mortality or other complications. In spite of significant differences in blunt injury type, injury severity, and the need for surgery, there were no significant differences in mortality or most postinjury complications between pediatric and adult patients with traumatic pancreatic injuries.
\end{abstract}

\section{Introduction}

Pancreatic trauma, although uncommon, is associated with high morbidity and mortality rates due to the location of the organ. ${ }^{1}$ While radiographic studies are the mainstay in diag-

* Both the authors contributed equally to this study. nosing pancreatic injury, these tests frequently fail to diagnose this injury. ${ }^{2}$ Adults who sustain pancreatic trauma may have a clinical presentation that is different from children. Furthermore, children may not be able to describe their symptoms as precisely as adults. ${ }^{3}$ Overlooking or misdiagnosing pancreatic trauma as a result of other intra-abdominal injuries can occur in both cohorts of patients since symptoms from other organ

Copyright $\odot 2017$ Georg Thieme Verlag License terms KG Stuttgart · New York

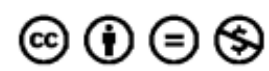

received
August 8, 2017
accepted after revision
September 8, 2017
Dol https://doi.org/

10.1055/s-0037-1607313. ISSN 2474-5871. 
injuries can present a confounding clinical picture. ${ }^{2}$ Nonoperative management has become more common in hemodynamically stable children with pancreatic injuries compared with adults. Understanding the differences in presentation and outcomes between these two groups would help physicians to more accurately identify, treat, and manage pancreatic injury patients. We performed this retrospective study to compare results between pediatric and adult patients suffering from traumatic pancreatic injuries. We hypothesized that adult patients would experience higher morbidity and mortality rates when compared with pediatric patients.

\section{Materials and Methods}

Patients included in this study were seen at four trauma centers (Cohen Children's Medical Center, Huntington Hospital, Staten Island University Hospital, and North Shore University Hospital), all of which are part of the Northwell Health System in New York, from 1990 to 2014. Regulatory approval was obtained from the Northwell Health Institutional Review Board. Charts were retrospectively reviewed and the data entered into a Research Electronic Data Capture (REDCap) database.

Descriptive statistics were calculated by group: pediatric (younger than 18 years at the time of injury) or adult (18 years of age or older at the time of injury). Mean \pm standard deviation, median, 25th and 75th percentiles for continuous data, frequencies, and percentages for categorical data were calculated. The Mann-Whitney $U$-test was used to compare pediatric and adult patients for continuous variables. Either the chisquare test or Fisher's exact test, as deemed appropriate, was used to compare the two groups for categorical variables.

Time to presentation from injury was analyzed by applying standard methods of survival analysis, that is, computing the Kaplan-Meier's product-limit curves, where the data were stratified by group. No data were considered censored and groups were compared using the log-rank test. The median rates for each group were obtained from the Kaplan-Meier/product-limit estimates and their corresponding 95\% confidence intervals were computed using Greenwood's formula to calculate the standard error.

Intensive care unit (ICU) length of stay (LOS) and hospital LOS were both analyzed using the above-described survival methods; however, the event was discharged alive from ICU (or hospital), and those subjects who died while in the ICU (or hospital) were considered censored at their date of death.

A result was considered statistically significant at the $p<0.05$ level of significance. All analyses were performed using SAS version 9.4 (SAS Institute Inc., Cary, North Carolina, United States).

\section{Results}

In this study, 26 pediatric and 43 adult patients were included. Median ages were 11.4 and 42.3 years, respectively. There were significant differences in mechanism of blunt injury between pediatric patients and adults (motor vehicle
Table 1 Demographic characteristics

\begin{tabular}{|l|l|l|l|}
\hline Variable & $\begin{array}{l}\text { Pediatric } \\
\text { group }\end{array}$ & $\begin{array}{l}\text { Adult } \\
\text { group }\end{array}$ & -Value \\
\hline$N$ & 26 & 43 & N/A \\
\hline Age in y (median) & 11.4 & 42.3 & 0.000 \\
\hline $\begin{array}{l}\text { Number of comorbidities } \\
\text { (median) }\end{array}$ & 0.00 & 0.00 & N/A \\
\hline Male sex (\%) & 69.2 & 74.4 & 0.640 \\
\hline Race (\%) & 55.0 & 65.1 & 0.608 \\
\hline Caucasian & 15.0 & 14.0 & \\
\hline African American & 100.0 & 85.2 & 0.136 \\
\hline Ethnicity & \multicolumn{5}{|l}{} \\
\hline Non-Hispanic (\%) &
\end{tabular}

Abbreviation: N/A, not available.

collisions $[\mathrm{MVCs}]=17.4$ vs. $64.9 \%$, bicycle accidents $=43.5$ vs. $0.0 \% ; p$-value for both comparisons $<0.0001)$, median injury severity score (ISS) (6.5 vs. $12 ; p=0.030$ ), surgical management (30.8 vs. $67.4 \% ; p=0.003$ ), and postinjury pancreatitis ( 57.7 vs. $20.9 \% ; p=0.002$ ). Median hospital LOS was 5 versus 11 days $(p=0.005)$, respectively. There were no differences in mortality or other complications. Demographic information is shown in - Table 1; details of injury and treatment information, respectively, are shown in -Tables 2 and 3; and outcomes and complications are shown in - Table 4. Graphical representations of the trend in operative versus nonoperative management of traumatic pancreatic injuries during the study period are shown for

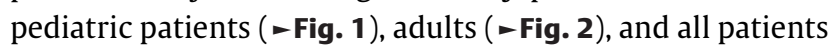
(-Fig. 3).

\section{Discussion}

The treatment approach to children with abdominal trauma differs significantly from that of adults. Force to the upper abdomen, commonly from bicycle handlebars or seat belts, as seen primarily in the pediatric population in our study, can compress the pancreas against the vertebral column. Children have a smaller body habitus which transmits traumatic force over a larger relative area than in adults. Although the pancreas is protected by abdominal musculature and anterior fat pads, these protective layers are thinner in children. ${ }^{4}$ The pediatric skeleton is more flexible, leading to the transmission of force to deeper and retroperitoneal abdominal structures. ${ }^{3}$ The absence of external signs of trauma cannot be used exclusively to rule out injury to abdominal organs. ${ }^{5}$ Due to the retroperitoneal location of the pancreas, injury is often wrongly attributed to other intra-abdominal organs, making the physical exam undiagnostic., ${ }^{2,6,7}$ Adults tend to engage in higher risk behavior and consequently derive pancreatic injuries from higher energy blunt trauma or penetrating trauma. ${ }^{2}$ Higher impact injuries may account for the greater injury severity, demonstrated by a higher median ISS in the adult compared with the pediatric group. 
e138 Outcomes in Pediatric versus Adult Pancreatic Trauma Patients lurcotta et al.

Table 2 Details of injury

\begin{tabular}{|c|c|c|c|}
\hline Variable & $\begin{array}{l}\text { Pediatric } \\
\text { group }\end{array}$ & $\begin{array}{l}\text { Adult } \\
\text { group }\end{array}$ & $p$-Value \\
\hline Blunt mechanism (\%) & 92.0 & 86.1 & 0.701 \\
\hline Penetrating mechanism (\%) & 8.0 & 14.0 & 0.701 \\
\hline \multicolumn{4}{|l|}{ Type of blunt mechanism ${ }^{a}(\%)$} \\
\hline Fall & 13.0 & 18.9 & \multirow[t]{4}{*}{$<0.0001$} \\
\hline MVC & 17.4 & 64.9 & \\
\hline Bicycle accident & 43.5 & 0.0 & \\
\hline Sports-related & 17.4 & 0.0 & \\
\hline \multicolumn{4}{|l|}{ Penetrating mechanism ${ }^{\mathrm{b}}(\%)$} \\
\hline Gunshot wound & 0.0 & 66.7 & \multirow[t]{3}{*}{0.214} \\
\hline Stab wound & 50.0 & 16.7 & \\
\hline Other & 50.0 & 16.7 & \\
\hline \multicolumn{4}{|l|}{ Pancreatic injury grade (\%) } \\
\hline 1 & 68.2 & 48.7 & \multirow[t]{5}{*}{0.181} \\
\hline 2 & 4.6 & 25.6 & \\
\hline 3 & 18.2 & 15.4 & \\
\hline 4 & 9.1 & 5.1 & \\
\hline 5 & 0.0 & 5.1 & \\
\hline Radiologic diagnosis (\%) & 65.4 & 55.8 & 0.433 \\
\hline Surgical diagnosis (\%) & 26.9 & 53.5 & 0.031 \\
\hline \multicolumn{4}{|l|}{ Site of injury (\%) } \\
\hline Head & 23.5 & 39.4 & \multirow[t]{4}{*}{0.612} \\
\hline Neck & 23.5 & 12.1 & \\
\hline Body & 23.5 & 24.2 & \\
\hline Tail & 29.4 & 24.2 & \\
\hline $\begin{array}{l}\text { Time from injury to presentation } \\
\text { (median, h) }\end{array}$ & 12.5 & 0.6 & 0.006 \\
\hline \multicolumn{4}{|l|}{ Laboratory values (median) } \\
\hline Lipase & 419.0 & 153.0 & 0.070 \\
\hline Amylase & 155.0 & 75.0 & 0.009 \\
\hline AST & 40.0 & 70.0 & 0.272 \\
\hline ALT & 26.5 & 62.0 & 0.022 \\
\hline Alkaline phosphatase & 192.5 & 69.0 & 0.000 \\
\hline Total bilirubin & 0.5 & 0.8 & 0.273 \\
\hline $\mathrm{Hb}$ & 13.6 & 12.9 & 0.969 \\
\hline Hct & 39.2 & 39.7 & 0.303 \\
\hline Lactate & 13.4 & 3.2 & 0.012 \\
\hline $\mathrm{pH}$ & 7.1 & 7.3 & 0.153 \\
\hline Serum bicarbonate & 24.0 & 21.0 & 0.815 \\
\hline ISS (median) & 6.5 & 12.0 & 0.030 \\
\hline GCS (median) & 15.0 & 15.0 & 0.688 \\
\hline Blood transfusion on admission (\%) & 19.2 & 52.4 & 0.007 \\
\hline Median blood units transfused & 3.0 & 4.5 & 0.615 \\
\hline Associated chest injury (\%) & 11.5 & 48.8 & 0.002 \\
\hline Other abdominal injuries (\%) & 48.0 & 72.1 & 0.047 \\
\hline Head injury (\%) & 7.7 & 16.7 & 0.465 \\
\hline Spinal fractures (\%) & 3.9 & 9.5 & 0.642 \\
\hline Long bone fractures (\%) & 3.9 & 21.4 & 0.076 \\
\hline Pelvic fractures (\%) & 3.9 & 14.0 & 0.242 \\
\hline
\end{tabular}

Abbreviations: ALT, alanine aminotransferase; AST, aspartate aminotransferase; GCS, Glasgow's coma score; Hb, hemoglobin; Hct, hematocrit; ISS, injury severity score; MVC, motor vehicle collision. Note: Bold values indicate that the $p$-Value is less than 0.05 .

apercentages expressed are of blunt trauma patients.

${ }^{\mathrm{b}}$ Percentages expressed are of penetrating trauma patients.
Table 3 Treatment and operative information

\begin{tabular}{|c|c|c|c|}
\hline Variable & $\begin{array}{l}\text { Pediatric } \\
\text { group }\end{array}$ & $\begin{array}{l}\text { Adult } \\
\text { group }\end{array}$ & $p$-Value \\
\hline Operative management (\%) & 30.8 & 67.4 & 0.003 \\
\hline \multicolumn{4}{|l|}{ Operative approach ${ }^{\mathrm{a}}(\%)$} \\
\hline Open & 75.0 & 96.6 & \multirow[t]{2}{*}{0.112} \\
\hline Minimally invasive & 25.0 & 3.5 & \\
\hline Pancreatic resection $^{\mathrm{a}}(\%)$ & 75.0 & 35.7 & 0.103 \\
\hline \multicolumn{4}{|l|}{ Type of resection ${ }^{\mathrm{b}}(\%)$} \\
\hline Distal pancreatectomy & 83.3 & 90.0 & \multirow[t]{2}{*}{1.000} \\
\hline Other resection & 16.7 & 10.0 & \\
\hline \multicolumn{4}{|l|}{ Other procedures $^{c}$} \\
\hline Drain placement & 3.9 & 20.9 & 0.077 \\
\hline Repair of injury & 3.9 & 9.3 & 0.643 \\
\hline Evacuation of hematoma & 0.0 & 9.3 & 0.289 \\
\hline Negative laparotomy & 0.0 & 4.7 & 0.523 \\
\hline Other procedure & 0.0 & 14.0 & 0.076 \\
\hline Endoscopic procedure & 15.4 & 14.3 & 1.000 \\
\hline
\end{tabular}

Note: Bold values indicate that the $p$-Value is less than 0.05 .

${ }^{a}$ Percentages are based on patients who were treated operatively.

bercentages are based on patients who had pancreatic resections.

'Percentages are based on total sample size.

Table 4 Outcomes and complications

\begin{tabular}{|c|c|c|c|}
\hline Variable & $\begin{array}{l}\text { Pediatric } \\
\text { group }\end{array}$ & $\begin{array}{l}\text { Adult } \\
\text { group }\end{array}$ & $p$-Value \\
\hline \multicolumn{4}{|l|}{ Mortality status } \\
\hline Dead (\%) & 3.9 & 20.9 & 0.077 \\
\hline \multicolumn{4}{|l|}{ Cause of death (\%) } \\
\hline CVA & 0.0 & 12.5 & \multirow[t]{3}{*}{1.000} \\
\hline Shock & 0.0 & 50.0 & \\
\hline Other & 100.0 & 37.5 & \\
\hline ICU admission (\%) & 61.5 & 76.7 & 0.177 \\
\hline $30 \mathrm{~d}$ readmission (\%) & 12.0 & 2.38 & 0.143 \\
\hline $\begin{array}{l}\text { Surgery } 30 \mathrm{~d} \text { after } \\
\text { discharge (\%) }\end{array}$ & 4.0 & 2.4 & 1.000 \\
\hline \multicolumn{4}{|l|}{ Postinjury complications } \\
\hline Pancreatitis (\%) & 57.7 & 20.9 & 0.002 \\
\hline Pancreatic pseudocyst (\%) & 3.9 & 4.7 & 1.000 \\
\hline Pancreatic hematoma (\%) & 11.5 & 11.6 & 1.000 \\
\hline Pancreatic necrosis (\%) & 11.5 & 4.7 & 0.358 \\
\hline Pancreatic abscess (\%) & 0.0 & 2.3 & 1.000 \\
\hline Endocrine insufficiency (\%) & 0.0 & 7.0 & 0.285 \\
\hline Exocrine insufficiency (\%) & 0.0 & 0.0 & $\mathrm{~N} / \mathrm{A}$ \\
\hline $\begin{array}{l}\text { Intra-abdominal fluid } \\
\text { collection (\%) }\end{array}$ & 50.0 & 48.8 & 0.925 \\
\hline TPN requirement (\%) & 34.6 & 39.0 & 0.716 \\
\hline ICU length of stay (median, d) & 3.0 & 5.0 & 0.287 \\
\hline Hospital LOS (median, d) & 5.0 & 11.0 & 0.005 \\
\hline
\end{tabular}

Note: Bold values indicate that the $p$-Value is less than 0.05 .

Abbreviations: CVA, cerebrovascular accident; ICU, intensive care unit; LOS, length of stay; N/A, not available; TPN, total parenteral nutrition. 


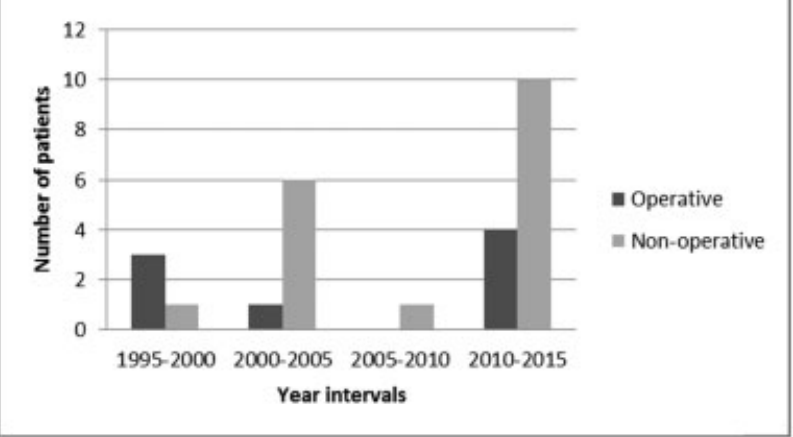

Fig. 1 Management trend (operative vs. nonoperative) of pediatric patients with time.

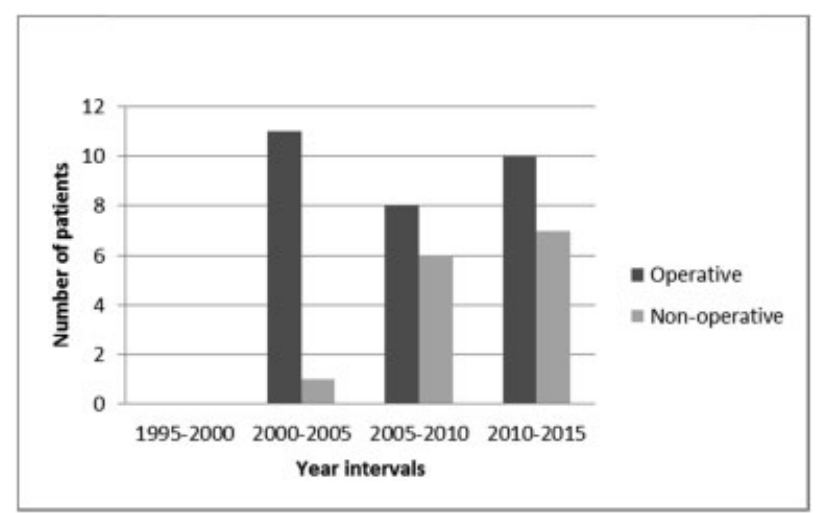

Fig. 2 Management trend (operative vs. nonoperative) of adult patients with time.

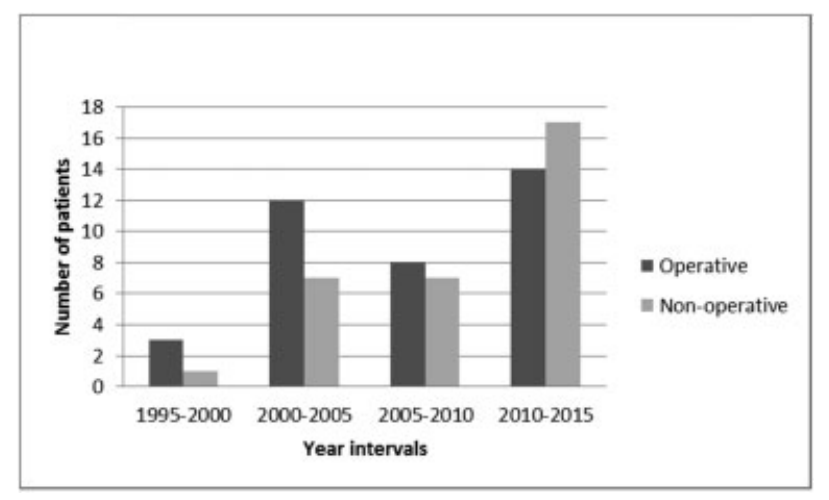

Fig. 3 Management trend (operative vs. nonoperative) for all patients with time.

Adults involved in MVCs are more likely drivers, and impact from the steering wheel can compress the upper abdomen, leading to injury. In falls, adults are more likely engaged in construction work and fall greater distances.

Delayed diagnosis and treatment of pancreatic trauma leads to greater morbidity and mortality, and this is well established in the literature; ${ }^{8-12}$ however, laboratory abnormalities are not clinically significant for pancreatic injury until hours after the trauma. In 1978, Jones first reported on the positive correlation between time of pancreatic injury and rise in serum amylase, suggesting that amylase levels increased 2 hours posttrauma. ${ }^{13}$ Takishima et al found that hyperamylasemia, suggestive of pancreatic injury, occurred 3 hours posttrauma at the earliest. ${ }^{14} \mathrm{~A}$ recent report concluded that amylase was not diagnostic of pancreatic injury until 6 hours posttrauma, regardless of the grade of injury. ${ }^{15}$ In our study, the time from injury to presentation was considerably longer for children than adults, and serum amylase levels were notably more elevated. This delayed presentation and resulting increase in amylase levels could be responsible for the significantly higher diagnosis of postinjury (acute) pancreatitis in the children, since elevated amylase three times the upper limit of normal is part of the diagnostic criteria. In a recent Australian study of 2,580 patients investigating the utility of lipase as a marker for pancreatic trauma, the authors concluded that elevated lipase did not reliably correspond with pancreatic injury. ${ }^{16}$

In 2009, the Eastern Association for the Surgery of Trauma issued guidelines for the management of pancreatic trauma. Injuries without ductal involvement (grades I and II) are best managed with drainage alone; injuries with ductal involvement (grade III) would benefit from both resection and drainage; and more severe injuries (grades IV and V) had no recommendations made. ${ }^{17}$ These guidelines are useful in the clinical decision making for isolated traumatic pancreatic injuries, but the recommendations are based chiefly on adult patient data. There is currently no clear consensus on when surgery is superior to the nonoperative management of pediatric pancreatic trauma patients. In a study of 26 pediatric patients with blunt pancreatic injury, Bass et al found an increased risk of pancreatic-specific complications with injuries involving the pancreatic duct, therefore, advocating for the nonoperative management of ductsparing injuries and surgery for those involving the duct. ${ }^{18}$ Shilyansky et al advocated for nonoperative strategies for both pancreatic contusion and transection injuries (likely grades III and IV); however, this group did not note the exact injury grade or if injuries involved the duct. ${ }^{19}$ Nadler et al found lower rates of complication and shorter lengths of hospital stay with earlier operative management of transecting injuries or those with major duct involvement; however, this group also did not separately analyze ductal involvement as a key variable for operative management. ${ }^{20}$ In a recent analysis of 167 pediatric patients suffering from blunt pancreatic trauma, operative management of duct-involving injuries resulted in a lower rate of pseudocyst formation, thus predisposing to faster returns to oral feeding, shorter LOS, fewer interventions, and more rapid resolution. If injuries did not involve the pancreatic duct, both management strategies yielded similar outcomes. ${ }^{21}$ Overall, these studies are difficult to compare due to the lack of specific detail about the pancreatic injury and scoring using the American Association for the Surgery of Trauma injury scoring scale.

We found that adults were more likely to be managed operatively and children more likely to be managed nonoperatively regardless of the pancreas-specific injury. However, adults were more severely injured based on ISS, and the presence of hemodynamic instability or other intra-abdominal injuries likely contributed to the difference in management strategies. 
The median hospital LOS in our study was shorter for the pediatric patients. In a recent retrospective study, Siboni et al observed that hospital LOS depended on both trauma severity and management strategy. Milder injuries, graded 2 on the organ injury scale (OIS), treated nonoperatively led to shorter LOS. However, more severe injuries (OIS 3-5) managed nonoperatively led to longer LOS. ${ }^{22}$ The higher frequency of operative management in adults, and the increased severity of injury, may have contributed to longer LOS in this population.

A total of $52.4 \%$ of adults and only $19.2 \%$ of children received blood transfusions $(p=0.007)$. The higher number of adults undergoing surgery (i.e., intraoperative blood loss leading to transfusions) may explain this difference. However, the groups did not differ on number of units transfused. On bivariate regression analysis, blood transfusion requirement and volume transfused correlate with both morbidity and mortality. On multivariate regression analysis, however, only volume transfused remained a significant predictor of mortality. ${ }^{23}$

A recent review of the National Trauma Data Bank showed that 1,600 children with blunt pancreatic injury suffered major complications in more than $25 \%$ of cases, including acute respiratory distress syndrome and pneumonia. ${ }^{24}$ Since major trauma databases do not collect data on pancreasspecific complications such as pancreatic fistulas and pseudocysts, data for these complications are limited to small retrospective reviews. Morbidity rates have, therefore, ranged from 8 to $60 \% .{ }^{11}$ We found that only postinjury pancreatitis differed significantly between children $(57.7 \%)$ and adults (20.9\%; $p=0.002)$. The major theory for this specific complication is the autophagy hypothesis: Pancreatic digestive enzymes are released due to splanchnic ischemia or pancreatic necrosis, ${ }^{15}$ causing a dysregulation of enzyme secretion, premature protease activation, and an inflammatory response. ${ }^{25}$ Since children are more often treated nonoperatively, retaining their pancreatic tissue, disruption of blood flow, or inflammation would release self-digestive enzymes and subsequently cause pancreatitis. Acute pancreatitis could have also been diagnosed more in children due to their significantly higher amylase levels at presentation to hospital.

Abscesses and fistulas occur at a rate of approximately $20 \%$, and are treated with antibiotics, computed tomography-guided drainage, and total parenteral nutrition (TPN) if necessary. ${ }^{26}$ A review of 134 patients with pancreatic injury by Patton et al found that both fistulas and abscesses are associated with ductal injury via multivariate analysis. ${ }^{27}$ Our cohort had no significant difference in ductal involvement between pediatric and adult patients, and subsequently had no difference in the development of pseudocysts and abscesses. Other complications such as fluid collections and TPN requirements did not differ significantly between the two groups.

Difference in mortality rate was not significant; $3.9 \%$ in the pediatric and $20.9 \%$ in the adult group $(p=0.077)$. Reports of mortality following pancreatic injury have ranged from 12 to $35 \% .^{9,28}$ The previously discussed review of the
National Trauma Data Bank for pediatric blunt pancreatic trauma found a mortality of $2.5 \%$, specifically for operatively managed patients, and $6.7 \%$ for nonoperatively managed patients. ${ }^{24}$ Cause of death also did not differ significantly between the pediatric and adult populations, likely due to the overall low mortality rate in our data. Improvements in surgical and critical care, restrictive transfusion strategies, and overall auxiliary care have led to a significant decrease in mortality and debilitation from injuries and operations.

Though multiple investigations have examined the management and outcomes of pancreatic trauma, our study is one of the few to have compared the specific injury details, treatment, complications, and outcomes of pancreatic injuries between children and adults. Our sample size of 69 patients is considerable given the rarity of these injuries in trauma presenting to the emergency department. We were able to accrue relatively large numbers of pediatric patients due to inclusion of the trauma records from a dedicated children's hospital with a level I trauma center. Our data are representative of four hospitals from a variety of geographical locations spanning two boroughs of New York City in addition to Long Island, which makes our results fairly generalizable.

Our study suffers from important limitations. First, the study is retrospective with data collected from more than two decades of treatment of pancreatic injuries in four trauma centers. Patient management strategies can differ significantly by surgeon, hospital, region, and over time. Second, charts reviewed from the earlier time period often did not include detailed notes on the rationale for surgical intervention. It was sometimes unclear whether surgery resulted due to failed nonoperative management, which would skew results toward surgery as a first line of treatment. Future studies that categorize cases of nonoperative, operative, and nonoperative-turned-operative management within each age group would allow for valuable analyses regarding complications, morbidity and mortality, and could change the management strategies.

\section{Conclusion}

In conclusion, although the pediatric and adult groups had significant differences in types of blunt pancreatic injury, time from pancreatic injury to presentation, injury severity, presence of other chest and abdominal injuries, need for operative management, blood transfusion requirement, and hospital LOS, the groups demonstrated comparable outcomes in terms of postinjury complications and mortality. The similar results between the pediatric and adult population may be due to improvements in surgical and critical care over time, which would require a time-trend analysis to confirm.

\section{Conflict of Interest}

None.

\section{Acknowledgment}

The authors would like to acknowledge the efforts of Mrs. Renee Cercone in editing this article. 


\section{References}

1 Jacombs AS, Wines M, Holland A, Ross FI, Shun A, Cass DT. Pancreatic trauma in children. J Pediatr Surg 2004;39(01):96-99

2 Debi U, Kaur R, Prasad KK, Sinha SK, Sinha A, Singh K. Pancreatic trauma: a concise review. World J Gastroenterol 2013;19(47): 9003-9011

3 Takishima T, Sugimoto K, Asari Y, et al. Characteristics of pancreatic injury in children: a comparison with such injury in adults. J Pediatr Surg 1996;31(07):896-900

4 Gupta A, Stuhlfaut JW, Fleming KW, Lucey BC, Soto JA. Blunt trauma of the pancreas and biliary tract: a multimodality imaging approach to diagnosis. Radiographics 2004;24(05):1381-1395

5 Kissoon N, Dreyer J, Walia M. Pediatric trauma: differences in pathophysiology, injury patterns and treatment compared with adult trauma. CMAJ 1990;142(01):27-34

6 Ilahi O, Bochicchio GV, Scalea TM. Efficacy of computed tomography in the diagnosis of pancreatic injury in adult blunt trauma patients: a single-institutional study. Am Surg 2002;68(08): 704-707, discussion 707-708

7 Akhrass R, Yaffe MB, Brandt CP, Reigle M, Fallon WF Jr, Malangoni MA. Pancreatic trauma: a ten-year multi-institutional experience. Am Surg 1997;63(07):598-604

8 Cirillo RL Jr, Koniaris LG. Detecting blunt pancreatic injuries. J Gastrointest Surg 2002;6(04):587-598

9 Kao LS, Bulger EM, Parks DL, Byrd GF, Jurkovich GJ. Predictors of morbidity after traumatic pancreatic injury. J Trauma 2003;55 (05):898-905

10 Bradley EL III, Young PR Jr, Chang MC, et al. Diagnosis and initial management of blunt pancreatic trauma: guidelines from a multiinstitutional review. Ann Surg 1998;227(06):861-869

11 Lin BC, Chen RJ, Fang JF, Hsu YP, Kao YC, Kao JL. Management of blunt major pancreatic injury. J Trauma 2004;56(04):774-778

12 Wisner DH, Wold RL, Frey CF. Diagnosis and treatment of pancreatic injuries. An analysis of management principles. Arch Surg 1990;125(09):1109-1113

13 Jones RC. Management of pancreatic trauma. Ann Surg 1978;187 (05):555-564

14 Takishima T, Sugimoto K, Hirata M, Asari Y, Ohwada T, Kakita A. Serum amylase level on admission in the diagnosis of blunt injury to the pancreas: its significance and limitations. Ann Surg 1997; 226(01):70-76

15 Mahajan A, Kadavigere R, Sripathi S, Rodrigues GS, Rao VR, Koteshwar P. Utility of serum pancreatic enzyme levels in diag- nosing blunt trauma to the pancreas: a prospective study with systematic review. Injury 2014;45(09):1384-1393

16 Mitra B, Fitzgerald M, Raoofi M, Tan GA, Spencer JC, Atkin C. Serum lipase for assessment of pancreatic trauma. Eur J Trauma Emerg Surg 2014;40(03):309-313

17 Bokhari F, Phelan H, Holevar M, et al. EAST Guidelines for the Diagnosis and Management of Pancreatic Trauma. Chicago: Eastern Association for the Surgery of Trauma; 2009

18 Bass J, Di Lorenzo M, Desjardins JG, Grignon A, Ouimet A. Blunt pancreatic injuries in children: the role of percutaneous external drainage in the treatment of pancreatic pseudocysts. J Pediatr Surg 1988;23(08):721-724

19 Shilyansky J, Sena LM, Kreller M, et al. Nonoperative management of pancreatic injuries in children. J Pediatr Surg 1998;33(02): 343-349

20 Nadler EP, Gardner M, Schall LC, Lynch JM, Ford HR. Management of blunt pancreatic injury in children. J Trauma 1999;47(06): 1098-1103

21 Iqbal CW, St Peter SD, Tsao K, et al; Pancreatic Trauma in Children (PATCH) Study Group. Operative vs nonoperative management for blunt pancreatic transection in children: multi-institutional outcomes. J Am Coll Surg 2014;218(02):157-162

22 Siboni S, Kwon E, Benjamin E, Inaba K, Demetriades D. Isolated blunt pancreatic trauma: a benign injury? J Trauma Acute Care Surg 2016;81(05):855-859

23 Krige JE, Kotze UK, Setshedi M, Nicol AJ, Navsaria PH. Prognostic factors, morbidity and mortality in pancreatic trauma: a critical appraisal of 432 consecutive patients treated at a Level 1 Trauma Centre. Injury 2015;46(05):830-836

24 Englum BR, Gulack BC, Rice HE, Scarborough JE, Adibe OO. Management of blunt pancreatic trauma in children: review of the National Trauma Data Bank. J Pediatr Surg 2016;51(09): 1526-1531

25 Binker MG, Cosen-Binker LI. Acute pancreatitis: the stress factor. World J Gastroenterol 2014;20(19):5801-5807

26 Ahmed N, Vernick JJ. Pancreatic injury. South Med J 2009;102(12): 1253-1256

27 Patton JH Jr, Lyden SP, Croce MA, et al. Pancreatic trauma: a simplified management guideline. J Trauma 1997;43(02):234-239, discussion 239-241

28 Strobel O, Schneider L, Philipp S, Fritz S, Büchler MW, Hackert T. Emergency pancreatic surgery-demanding and dangerous. Langenbecks Arch Surg 2015;400(07):837-841 